\title{
Game as a scientific and methodological basis of modern geodetic education
}

\author{
Anastasia Dudnik* and Galina Tupoleva \\ Don State Technical University, 344022, Rostov-on-Don, Russia
}

\begin{abstract}
Modern level of scientific and technical development in the field of geodetic and cartographic activity associated with the use of satellite geodetic methods, the widespread introduction of new technical means and technologies, requires highly qualified specialists who are able to solve complex production and scientific problems in the field of geodesy. This is the reason for the new teaching methods' emergence. It is worth noting that the evaluative control implementation of knowledge, skills and abilities in a playful form allows the teacher to provide the necessary assistance to the student in a timely manner, to guide him, develops and activates the independent work of students, and also creates comfortable conditions for successful mental activity formation.
\end{abstract}

\section{Introduction}

Modern Russian higher education is characterized by the presence of an objective contradiction between the existing lecture and seminar methodology of mastering the general educational program of the state educational standard by the students and the need for practice in the complex application of the acquired knowledge by the university graduates [1]. The lecture-seminar methodology for mastering academic disciplines ensures the formation of students' knowledge, abilities, skills in each discipline separately. At the same time, the future practical activity of the student requires him to comprehensively apply the received narrow professional knowledge in relation to current situations on the basis of formed universal competencies, the side of this contradiction is the ratio between passive and active teaching methods established by the state educational standard. This ratio establishes the proportions between study time devoted to passive teaching methods, such as lectures, films, visual aids, printed materials, any combination of these means and study time devoted to active teaching methods, such as laboratory work, seminar, practical lesson, practice, internship, use of simulators, situation analysis, game, etc. This actualizes the search for new approaches to improving education.

At the same time, the modern level of scientific and technical development in the field of geodetic and cartographic activities associated with the use of satellite geodetic methods, the widespread introduction of new technical means and technologies, requires even more the presence of highly qualified specialists capable of solving complex production and scientific problems in the field of geodesy. A modern specialist is faced with new

\footnotetext{
*Corresponding author: Nasty777@bk.ru
} 
requirements in the field of geo-industry, which, along with basic knowledge in the field of geo-space, must have the competence of analyst, management, marketing and WEB programming. In recent decades, technologies for the use of global navigation satellite systems in performing geodetic and navigation tasks have been rapidly developing, electronic tacheometry is being improved, new methods and technologies of digital photogrammetry are emerging, experience is accumulated in the practical use of ground and air three-dimensional laser scanning, spatial data of remote sensing of the Earth from space; geoinformation technologies have become widespread, allowing to solve in a new way not only the tasks of traditional mapping, but also to create and analyze the spatial models of the real world, etc. Unfortunately, these skills cannot be obtained in classical lecture and laboratory education.

For more effective training, the authors propose to introduce "Game" into the training program as scientific and methodological basis and use it as a form of control [2]. Of course, the assessment of this form of control excludes the usual five-point marks, but it will give students the opportunity to prove themselves.

\section{Results}

Assessment given in the process of observing the ongoing work in the team allows the teacher and the student to track progress towards achieving learning goals, and they can be approached in various ways. It is worth noting which method will be more effective in assessing students depends primarily on the discipline taught, educational standards and the level of students' knowledge. A huge layer of modern research is devoted to the geodatabase accounting development. The game is used in modern geodetic education as a scientific and methodological basis. The game method of controlling students' knowledge, abilities and skills motivates the students to work independently, activates their educational and cognitive activities. When students feel more motivated to learn - in other words, when participation is at a high level - they learn better and gain a higher sense of self-esteem. Unfortunately, the data and direct experience of many teachers show that the lack of motivation affects many students [1].

Therefore, this study is of great practical value. It consists in its implementation of the educational process, as well as in conducting further research in this area, ways of solving and improving the methodology for assessing students' knowledge.

The relevance of the study is due to the fact that in modern higher education more and more hours are devoted to independent work, including applied disciplines such as geodesy. The mental load grows, students lose interest and motivation in the subject. For this reason, the teacher tries to introduce the new methods and technologies in the educational process, activating and encouraging students to work not only in the classroom, but also in the independent search for new knowledge. One of such interesting techniques can be safely called game methods.

Groups of 3rd year students were taken as the object of research. The subject studied by the students belongs to the disciplines of the professional cycle of the specialty "Applied Geodesy". In this connection, we note that the discipline is not easy to study, full of various technical terminology. After studying several sections of the discipline, and performing laboratory work, it was decided to conduct a survey and evaluate the knowledge and skills of students in the form of a game.

In the general case, a game is understood as a form of human activity in conditional situations, aimed at recreating and mastering social experience, fixed in socially fixed ways of implementing the objective actions [7]. The game is based on the real imitationprocesses and the conditions for their implementation in order to form the participants of the game competencies [8] corresponding to the tasks of the game. 
Simulation of real processes in a game is always carried out on the basis of the use of game simulation models that represent the real process or the conditions for its implementation in some simplified form.

There are three methods in play activity:

- business game;

- role play;

- collective game activities.

The most difficult of them and, at the same time, the most versatile, flexible and effective is the method of the business game [9]. A business game is understood as an active teaching method that uses imitation of a real studied object or process to create the fullest sense of real activity for the students when they perform their respective role functions.

The business game as a teaching method is distinguished by the following features:

1. Imitation of objects and processes of the activity subject area based on the use, firstly, of a complex of simulation models, and second, by imitating the electronic working environment of the activities of specialists, and third, by imitating the specialists' information interaction environment.

2. Realization of a game contradiction between game participants in the form of partnership, opposition, competition, rivalry, confrontation, competition, competition, auction, conflict.

3. The interconnection of the goals and objectives of the game, with the competencies of specialists provided for by federal state educational standards, which ensures the game systemunity.

4. Availability of subject and procedural rules of the game.

5. Distribution of game participants by roles and game teams, in accordance with which the performance of their role functions and interaction with each other are organized.

6. The probabilistic nature of events and situations realized by the participants in the game. Events, as in real life, are not deterministic. The probabilistic nature of the game is ensured by the introduction of elements of risk and uncertainty. Elements of risk and uncertainty are introduced by providing input to the game participants containing either incomplete (distorted) information.

7. Using of the flexible time frames: astronomical, compressed or extended as appropriate. The compressed time frame gives an opportunity to "play" many cycles of activity in a short study time. An extended time frame, on the other hand, permits the ability to split the cycle and view it in greater detail. Combined use of playing time scales is achieved through the use of operational time jumps.

8. The activities of players and game teams are assessed based on a special rating system.

9. A system of incentives is established for the participants in the game, which contributes to the emergence of real interest in them.

10. The presence of an information space [10] as a prerequisite for the dynamic information situations' simulation [11].

An important component is the preliminary preparation for the game. For this reason, the students were notified about this form of assessment control a week before the scheduled date of the game. At the same time, the rules of the game were not explained in advance.

The process of the game itself is described below. The students were given: the topic of the game, the names of the lectures and laboratory work sections, for which it is necessary to prepare. The whole group was divided into teams of 4-5 people and consistently performed tasks: question-answer cards, a crossword puzzle, a practical task. Each task was graded with appropriate points. 
Having studied the works of fellow teachers, adopting their experience in organizing the assessment of students' knowledge and skills using the game method of control, as well as on the personal experience basis $[1,2]$, we will describe the basic requirements for the game (quiz) organization in the classroom:

1. The structure and form of the game should enable each student to prove himself, show his potential, independence, ingenuity.

2. The game should be structured in such a way that students show interest, be active, show good mood and satisfaction with a brilliant answer.

3. The main goal of the game must be feasible.

4. A prerequisite for the game conduct is the presence of a competitive element between the teams and individual participants, as well as strict adherence to the gamerules.

5. Winning the game is a powerful incentive for students, inspiring and motivating them [2].

Based on the results of the study, the following should be noted:

1. It turned out to be difficult to assess the knowledge and skills of each specific student of the team, since it was impossible to trace the share of his participation in the game.

2. The students were active, interested and they liked this form of lesson, instead of the usual test work. Friendly competition in the group was created.

3. Using a quiz or game is a fun way to assess what students already know, clear up misconceptions and learning challenges and gaps along the way.

4. Since the game contained a combination of theory and practice, it was a more objective reflection of reality, and the material was better assimilated [1].

According to the study results, the 2nd group of 3rd year students who underwent control of learning in a game form had better results than students of the same specialty of the last year of study (Fig.1).

\section{Analysis of the results of monitoring student progress}

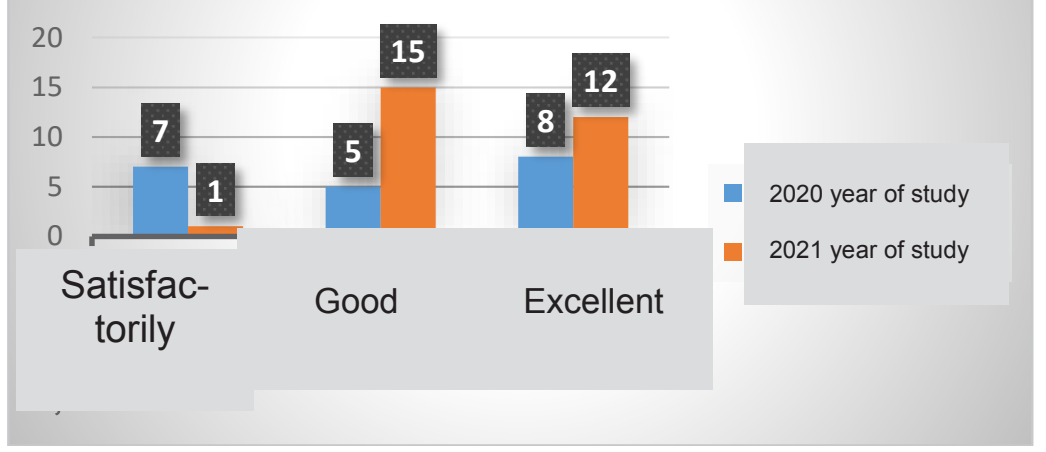

Fig. 1. Analysis of the results of monitoring student progress

The authors propose to introduce a play form into the entire learning process, not only as a control. 2 groups of students of one specialty were selected as the object of research. One group is trained in the classical program, the second group in laboratory classes in one of the core subjects, is trained in the form of a business game.

The group is united into a geodetic brigade, which advises the maximum for real work. The students assigned the roles in the brigade themselves, such experience helps to unite the team, identify the leaders, show the students their best qualities. Classes are held in the form of a meeting with a teacher, where students ask a question and demonstrate the results. 
The teacher also sets the task for implementation. For the 3rd year students, this is the preparation of a geodetic report, the data for which they measure independently, and the documentation is received upon request from the MPSC. At each new laboratory lesson, the teams receive a task that cannot be completed without completing the previous work. Thus, by the end of the semester, the group prepares a real report and defends it in front of the teacher and teammates. It provides an opportunity for the students to gain public speaking skills.

At the same time, the teacher has the opportunity to observe and evaluate the collective work. One of the business game goals is to bridge the semantic gap between the teacher and students [10]. According to the observation data, it is already possible to draw the conclusions that $85 \%$ of students were more involved in the learning process, studied the material, including independently, and showed themselves in class. At the same time, the revealed knowledge will serve as a foundation for the students on educational practices and in the study of other general professional disciplines.

\section{Conclusion}

The rapid changes in the modern world have caused the higher education system to face many challenges. Therefore, training is required for more active, versatile developed and educated persons in interdisciplinary fields. Thus, the research to identify useful and effective teaching methods is one of the most important tasks of educational systems. The game method is the most effective in assessing the work of students in practical classes. In the game, students feel themselves to be carriers of active knowledge acquisition, they involve all channels of information perception.

The theoretical significance of the research performed lies in the formation of the scientific and methodological foundations of the technological development of geodesy, which characterize the integrity of scientific ideas about its technological development. At the same time, the business game method allows solving a number of topical problems of training surveyors:

1. The problem of the trainees' competencies formation [8] for the situations that cannot be reproduced in reality either because of high costs, or because of long (short) terms of implementation of processes, or because of the number and complexity of the objects and processes used (in including hypothetical), or because of the threat to human life and health.

2. The problem of students gaining experience in research and production activities in the shortest possible time at the lowest cost through the use of simulation models.

3. The problem of management in distributed environments, in particular network management [10].

4. The problem of the role-based and situational teaching methods practical implementation, as well as their combination. Game is always role-playing as the participants are drawn into a prescribed situation. At the same time, the game stimulates the participants to systemic and situational analysis in relation to the situation being played out.

5. The problem of accumulation in digital form and adaptation of teaching materials of highly specialized disciplines in relation to subject activity areas.

The possibility of developing and implementing training in a game form into practice is confirmed by the achieved level of methodological support for the development and conduct of business games.

To date, unfortunately, there is no holistic approach to assessing the geodetic education development, as to the formed scientific direction due to the lack of an ordered system of scientific and methodological foundations of its technological development; in this regard, 
it is impossible to carry out a systematic analysis of geodetic science to predict its further development, which certainly affects the quality of education. However, despite this fact, the "Game" as a method of practical education can solve this problem. Since the teacher has more modern tools, show new geodetic technologies, ask questions, captivate students, while getting a complete structured analysis of knowledge.

\section{References}

1. O.V. Germak, A.E. Dudnik, G.K. Tupoleva Modern Research of Social Problems (Electronic Scientific Journal) 9, 11-15 (2018).

2. A.A. Elenin, I.A. Kazakova, Scientific conference "Optimization of medical education: quality and innovation" (2015).

3. I.F. Kushtin, Geodesy (Prior, Moscow, 2001).

4. I.F. Kushtin, Engineering geodesy (Phoenix, Rostov-on-Don, 2002).

5. I.V. Soloviev, Education management: theory and practice 1, 10-16 (2013).

6. V.Ya. Tsvetkov, European Researcher 45 (4-1), 782-786 (2013).

7. S.A. Kudzh, I.V. Soloviev, V.Ya. Tsvetkov, Distance and virtual learning 11, 10-15 (2013).

8. I.V. Soloviev, Earth Sciences 01, 54-58 (2012).

9. V.Ya. Tsvetkov, European Researcher (36), 12-1, 2166- 2170 (2012).

10. A.N. Tikhonov, A.D. Ivannikov, I.V. Soloviev, V.Ya. Tsvetkov, S.A. Kudzh, The concept of network-centric control of a complex organizational and technical system (MAKS Press, Moscow, 2010).

11. S.S. Shipilova, Modern problems of science and education, 3 (2014). URL: http://science-education.ru/ru/article/view?id=13293 (accessdate: 11/14/2018).

12. V.Ya. Tsvetkov, Distance and virtual learning 5, 4- 11 (2014). 